${ }^{1}$ Soonchunhyang University College of Medicine, Division of Rheumatology, Department of Internal Medicine, Cheonan, Korea, Rep. of (South Korea); ${ }^{2}$ Clinical Research Center, Asan Institute for Life Sciences, Asan Medical Center, Department of Medical Stastics, Seoul, Korea, Rep. of (South Korea); ${ }^{3}$ GENOME INSIGHT Inc., -, Seoul, Korea, Rep. of (South Korea); ${ }^{4}$ Soonchunhyang University College of Medicine, Department of Radiology, Cheonan, Korea, Rep. of (South Korea); ${ }^{5}$ SMG-SNU Boramae Medical Center, Department of Radiology, Seoul, Korea, Rep. of (South Korea); ${ }^{6}$ Seoul National University Bundang Hospital, Division of Rheumatology, Department of Internal Medicine, Seongnam, Korea, Rep. of (South Korea): ${ }^{7}$ Kyung Hee University College of Medicine, Division of Rheumatology, Department of Internal Medicine, Seoul, Korea, Rep. of (South Korea); ${ }^{8}$ Yonsei University College of Medicine, Division of Rheumatology, Department of Internal Medicine, Seoul, Korea, Rep. of (South Korea); ${ }^{9}$ Catholic University of Daegu College of Medicine, Division of Rheumatology, Department of Internal Medicine, Daegu, Korea, Rep. of (South Korea); ${ }^{10}$ Seoul National University College of Medicine, Division of Rheumatology, Department of Internal Medicine, Seoul, Korea, Rep. of (South Korea)

Background: Interstitial lung disease (ILD) is a severe extra-articular manifestation of rheumatoid arthritis (RA). However, the effect of RA treatment on the course of ILD is not yet known.

Objectives: To assess the effect of RA treatment on the course of lung physiology of RA-focusing on biologic DMARDs treatment.

Methods: The Korean Rheumatoid Arthritis ILd (KORAIL) cohort is the prospective observational cohort and aims to investigate the natural course of RAILD. Based on either 1987 or 2020 ACR criteria, patients diagnosed with RA and ILD based on CT scan were recruited from six tertiary medical hospitals in Korea since January 2015. RA disease activity was assessed using disease activity (DAS)28-ESR and CRP, annually. Pulmonary function tests (PFT), including FVC and DLCO were conducted annually. In the current study, we analyzed patients who completed a 2-years follow-up or had died during those terms till October 2020. They classified patients into three groups: patients treated with abatacept $\geq 24$ weeks ever (Group 1), those with other bDAMRDs $\geq 24$ weeks ever (Group 2), and those without any bDMARDs or with bDMARDs $<24$ weeks (Group 3).

Results: Of a total of 125 patients who completed 2-year follow-up, 21 patients were classified as Group 1, 26 for Group 2, and 78 for Group 3. The mean age or the number of patients with $\geq 65$-year-old was comparable between groups(Table 1). The mean duration since RA diagnosis was shorter in Group 3, but that since ILD diagnosis was comparable. DAS28-ESR score was comparable between Group 1 and 2 at enrollment, so was in 1-year-follow-up $(p=0.75)$ and 2-year-follow-up $(p=1.00)$. FVC and \% of the predicted value in FVC, FEV1, and DLco were also comparable among the three groups at enrollment. The numbers of patients with $\geq 10$-point decline in \% of FVC predicted was 2 (10.0\%) for Group 1, $1(3.8 \%)$ for Group 2, $3(3.9 \%)$ for Group3 during the first 1-year follow-up, and $3(15.8 \%), 3(11.5 \%), 10(14.1 \%)$ during the last 1-year follow up. The percent of FVC predicted was $81.6 \pm 17.5 \%, 87.4 \pm 17.9 \%, 85.2 \pm 17.7 \%$ for Group 1,2 and 3 , respectively, at 1-year-follow-up, and $79.5 \pm 18.8 \%, 89.0 \pm 16.8 \%, 83.5$ $\pm 17.3 \%$ at 2-year-follow-up. (Figure $1 \mathrm{~A}$ ). The percent of DLco predicted was $75.5 \pm 23.4 \%, 66.7 \pm 18.1 \%, 67.5 \pm 16.7 \%$ for Group 1,2 and 3 , respectively, at 1-year-follow-up, and $74.0 \pm 23.7 \%, 69.1 \pm 18.9 \%, 67.0 \pm 18.5 \%$ at 1-year-follow-up (Figure 1B).

Conclusion: Treatment of bDMARDs did not exacerbate FVC than without bDMARDs treatment and mitigated the decline of DLCO compared to without bDMARDs treatment during 2-year-follow-up.

Table 1. Clinical characteristics at enrollment (V1)

\begin{tabular}{lccccc}
\hline & Total & Group 1. & Group 2. & Group 3. & P \\
\hline $\mathrm{N}$ & 125 & 21 & 26 & 78 & \\
Age at enrollment & $65.9 \pm 8.2$ & $66.0 \pm 8.8$ & $63.9 \pm 8.0$ & $66.6 \pm 8.1$ & 0.34 \\
65, $\mathrm{n}(\%)$ & $72(57.6)$ & $13(61.9)$ & $11(42.3)$ & $48(61.5)$ & 0.21 \\
Female, $\mathrm{n}(\%)$ & $89(71.2)$ & $16(76.2)$ & $17(65.4)$ & $56(71.8)$ & 0.71 \\
RA duration, years & $8.0 \pm 8.4$ & $9.6 \pm 6.6$ & $9.2 \pm 9.0$ & $7.2 \pm 8.6$ & 0.05 \\
ILD duration, years & $3.0 \pm 3.3$ & $3.8 \pm 3.7$ & $3.8 \pm 3.5$ & $2.5 \pm 3.1$ & 0.10 \\
BMl, kg/m2 & $24.1 \pm 3.1$ & $23.8 \pm 3.7$ & $24.8 \pm 2.9$ & $23.9 \pm 3.0$ & 0.39 \\
Ever-smoker & 18 & 5 & 5 & 18 & 0.57 \\
RF positive, $\mathrm{n}(\%)$ & $111(88.8)$ & $19(90.5)$ & $22(84.6)$ & $70(89.7)$ & 0.72 \\
Anti-CCP positive, & $119(95.2)$ & $20(95.2)$ & $25(96.2)$ & $74(94.9)$ & 1.00 \\
$\quad \mathrm{n}(\%)$ & & & & & \\
Arthritis activity & & & & & \\
DAS28-ESR & $4.0 \pm 1.4$ & $4.1 \pm 1.1$ & $4.3 \pm 1.8$ & $3.8 \pm 1.4$ & $0.60^{*}$ \\
DAS28-CRP & $3.1 \pm 1.4$ & $3.2 \pm 1.2$ & $3.4 \pm 1.6$ & $3.0 \pm 1.4$ & $0.76^{*}$ \\
HAQ-DI & $0.70 \pm 0.76$ & $0.64 \pm 0.49$ & $0.82 \pm 0.82$ & $0.67 \pm 0.80$ & 0.28 \\
Pulmonary function test & & & & & \\
FVC, ml & $2522.5 \pm 765.4$ & $2406.2 \pm 772.6$ & $2617.3 \pm 965.2$ & $2522.2 \pm 692.3$ & 0.65 \\
FVC, \% of pred. & $84.6 \pm 16.9$ & $80.9 \pm 17.7$ & $86.12 \pm 17.82$ & $85.08 \pm 16.5$ & 0.53 \\
FEV1, \% of pred. & $92.4 \pm 21.4$ & $92.0 \pm 24.8$ & $90.6 \pm 22.1$ & $93.0 \pm 20.4$ & 0.88 \\
DLco, \% of pred. & $71.5 \pm 19.7$ & $72.3 \pm 26.7$ & $69.1 \pm 16.4$ & $72.0 \pm 18.7$ & 0.80
\end{tabular}
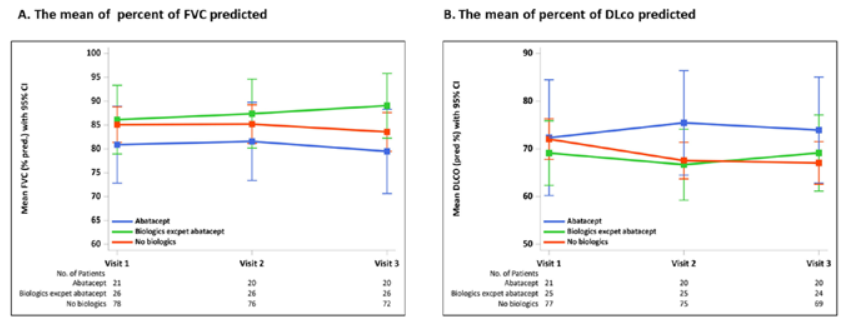

Figure 1.

Acknowledgements: This research was supported by Bristol Myers Squibb Inc Disclosure of Interests: Sung Hae Chang: None declared, Ji Sung Lee: None declared, Jeong Seok Lee: None declared, Chan Ho Park: None declared, Min Uk Kim: None declared, You-Jung Ha: None declared, Eun Ha Kang: None declared, Yeon Ah Lee: None declared, Yongbeom Park: None declared, JungYoon Choe: None declared, Eun Young Lee Grant/research support from: Bristol Myers Squibb Inc.

DOI: 10.1136/annrheumdis-2021-eular.3094

\section{POS0565 IS ACTIVE SYNOVITIS OF METACARPOPHALANGEAL JOINTS A NEUROPATHIC CONDITION IN RHEUMATOID ARTHRITIS PATIENTS? RESULTS FROM A ULTRASOUND STUDY AT LEVEL OF THE PALMAR DIGITAL NERVES}

M. Di Carlo ${ }^{1}$, J. Di Battista ${ }^{1}$, R. Chiorrini ${ }^{1}$, E. Cipolletta ${ }^{1}$, G. Smerilli ${ }^{1}$, A. Di Matteo $^{1}$, T. Okano ${ }^{2}$, F. Salaffi ${ }^{1}$, E. Filippucci ${ }^{1} .{ }^{1}$ Università Politecnica delle Marche, Dipartimento di Scienze Cliniche e Molecolari - Rheumatology Clinic, Jesi, Italy; ${ }^{2}$ Osaka City University Graduate School of Medicine, Department of Orthopedic Surgery, Osaka, Japan

Background: Rheumatoid arthritis (RA) is a chronic inflammatory arthritis that primarily affects the joints of hands, wrists, and feet. Anatomical damage (at bone, cartilage and tendon level) occurs as a consequence of a persistent synovial inflammation (1). In RA, periarticular soft tissues, including nerves, may also be involved. In particular, there is a high prevalence of neuropathic conditions such as carpal tunnel syndrome (CTS) in RA patients. In fact, the presence of inflammatory changes can frequently be documented by ultrasound (US) at the level of median nerve (2). Currently available very-high frequency US transducers allow high spatial resolution of small anatomical structures, including the palmar digital nerves. Objectives: The objectives of this study were: to document the presence of dimensional alterations of the palmar digital nerves, particularly in terms of increased cross-sectional area (CSA), and to determine the variables associated with increased CSA, in RA patients.

Methods: From September 2020 to December 2020, adult RA patients from a tertiary outpatient clinic were consecutively included regardless of disease activity status. Patients underwent a clinical assessment to determine disease activity using the Clinical Disease Activity Index (CDAI), functional capacity using the QuickDASH, and the presence of neuropathic pain features using the PainDetect Questionnaire (PDQ). In the same visit, patients underwent a US examination of the $2^{\text {nd }}$ to $5^{\text {th }}$ metacarpophalangeal joints (MCPj) of the clinically more involved hand by an operator blinded to the clinical assessment. The presence/absence and US grading of synovitis was recorded for each joint. A third operator, blinded to the clinical and joint US assessment, measured the CSA of each pair of palmar digital nerves from $2^{\text {nd }}$ to $5^{\text {th }}$ finger scanned for assessment joint involvement. The CSA of the palmar digital nerves was measured at the MCPj. The US examinations were conducted with a MyLab Class C (Esaote, Genoa, Italy), with a 6-18 $\mathrm{MHz}$ probe for the articular examination, and with an 10-22 $\mathrm{MHz}$ probe for the examination of the palmar digital nerves. The serological status, respectively rheumatoid factor (RF) and anti-citrullinated peptide antibodies (ACPA), and the presence of radiographic erosive disease were also recorded for each patient. Statistical analysis was conducted by considering the sum of the CSA for each nerve pair of each finger. CSA was compared with respect to body mass index (BMI), disease duration, disease activity, US synovitis grading, functional capacity, neuropathic pain features, serological characteristics, and erosive status. Results: Sixty-three patients with RA were included, 48 women, 15 men, with a mean age of 62.2 (11.8, standard deviation [SD]) years, a mean disease duration of 10.9 (8.2) years, for a total of $252 \mathrm{MCPj}$ and 504 palmar digital nerves. The CSA of the palmar digital nerves taken individually was $2.3(0.9) \mathrm{mm}^{2}$, ranging from $1 \mathrm{~mm}^{2}$ to $8 \mathrm{~mm}^{2}$, and $4.2(1.5) \mathrm{mm}^{2}$ as a pair for finger. There was a statistically significant association with disease activity as assessed by the CDAI ( $p$ $<0.001)$, and with the grading of US synovitis $(p<0.001)$, while there were no significant associations with any of the other variables. 
Conclusion: The presence of active RA, both in terms of clinical and ultrasonographic indices, correlates with an increased CSA of the palmar digital nerves. This alteration is probably due to inflammatory mechanisms of the perineural tissues at the level of the MCPj. Active synovitis during RA can somehow be framed as a condition capable of causing neuropathic damage to the palmar digital nerves. REFERENCES:

[1] Filippucci E, Cipolletta E, Mashadi Mirza R, et al. Ultrasound imaging in rheumatoid arthritis. Radiol Med 2019;124(11):1087-1100.

[2] Smerilli G, Di Matteo A, Cipolletta E, et al. Ultrasound assessment of carpal tunnel in rheumatoid arthritis and idiopathic carpal tunnel syndrome. Clin Rheumatol 2020; doi: 10.1007/s10067-020-05293-z.

Disclosure of Interests: None declared

DOI: 10.1136/annrheumdis-2021-eular.3116

\section{\begin{tabular}{|l|l}
\hline POS0566 CATASTROPHIZING IN PATIENTS WITH RHEUMATOID \\
\hline
\end{tabular} ARTHRITIS}

C. Traverson ${ }^{1}$, B. Coste $^{1}$, E. Filhol ${ }^{1,2}$, C. Daien ${ }^{3,4}$, S. Laurent-Chabalier ${ }^{5}$, S. Benamar ${ }^{3}$, B. Combe ${ }^{3,4}$, C. Lukas ${ }^{2,3}$, J. Morel ${ }^{3,4}$, C. Hua ${ }^{1,2}$, C. Gaujoux Viala ${ }^{1,2} .{ }^{1}$ Nîmes University Hospital, Rheumatology, Nîmes, France; ${ }^{2}$ University of Montpellier, IDESP, UMR-INSERM, Montpellier, France; ${ }^{3} \mathrm{CHU}$ Lapeyronie, Rheumatology, Montpellier, France; ${ }^{4}$ University of Montpellier, -, Montpellier, France; ${ }^{5}$ Nîmes University Hospital, BESPIM, Nîmes, France

Background: Catastrophizing is conceptualized as a negative cognitive-affective response to an anxiety-provoking stimulus, especially anticipated or actual pain. Catastrophizing can be assessed quickly using a validated questionnaire: the Pain Catastrophizing Scale (PCS) ${ }^{1}$. Catastrophizing plays a role in maintaining chronic pain and is associated with several pain-related outcomes in osteoarthritis and low back pain. Objectives: To assess the prevalence of catastrophizing and associated factors in rheumatoid arthritis (RA).

Methods: We performed an observational, prospective, bi-centric study. All patients aged 18 or over with RA and fulfilling the ACR-EULAR 2010 criteria were consecutively included. Sociodemographic data, information on the disease and its treatments were collected as well as questionnaires for disease activity (DAS28), function (HAQ), quality of life (SF12, EQ5D), anxiety and depression (HADS, GAD7), fibromyalgia (FiRST), insomnia (ISI) and catastrophizing scores (PCS). Statistical analysis included the samples t-test, one-way variance analysis, the Spearman's correlation test, the Chi ${ }^{2}$ test, Fisher's exact test, the Wilcoxon test, multivariate linear regression (considering catastrophizing as a continuous variable) and multivariate logistics regression (considering catastrophizing as a categorical variable: $P C S \geq 20=$ high level catastrophizing). Results: From September 2019 to March 2020, 201 patients with RA were included: $78.1 \%$ were women and the median age was 63.0 years. In all, $64.1 \%$ of patients were RF+, $65.7 \%$ ACPA+, and $46 \%$ had erosive disease. Median DAS28 CRP was 2.9 [2.1-4.0]. with $45 \%$ of patients in remission, $14.8 \%$ with low, $31.2 \%$ moderate and $9 \%$ high activity. The majority of patients (92\%) had a disease lasting for more than 2 years.

The prevalence of a PCS score $\geq 20$ was $48.0 \%$ [41.0;54.9]. The median PCS score was 18 [7-28]. In multivariate logistics regression, high-level catastrophizing was significantly associated with DAS28-CRP (OR=1.61 [1.18-2.20]), HADS anxiety score $(\mathrm{OR}=1.25[1.11-1.40])$ and the HADS depression score $(\mathrm{OR}=1.19$ [1.07-1.33]). In multivariate linear regression, catastrophizing was significantly associated with the HADS anxiety score $(p<0.0001)$, HADS depression score $(p=0.0055), H A Q(p=0.0015)$ and the ISI insomnia score $(p=0.005)$.

Conclusion: Almost half the patients with RA were high catastrophizers. Catastrophizing is linked to anxiety, depression, disease activity, function impairment and insomnia. It may be interesting to detect catastrophizing in order to improve the management of our patients.

REFERENCES:

[1] Sullivan MJL. et al. Psychological Assessment. 1995;7(4):524-32

Disclosure of Interests: None declared

DOI: 10.1136/annrheumdis-2021-eular.3144

\section{POS0567 HEPCIDIN IS POTENTIAL BIOMARKER TO DISTINGUISH BETWEEN IRON DEFICIENCY ANEMIA AND ANEMIA OF INFLAMMATION IN RHEUMATOID ARTHRITIS}

E. Galushko ${ }^{1}$, A. Semashko ${ }^{1}$, A. Gordeev ${ }^{1}$, A. Lila ${ }^{1}{ }^{1}$ V.A.Nasonova Research Institute of Rheumatology, Department of Early Arthritis, Moscow, Russian Federation

Background: Anemia of inflammation (AI) and iron deficiency anemia (IDA) are the two most prevalent forms of anemia in patients with rheumatoid arthritis (RA). Diagnosis becomes challenging if $\mathrm{Al}$ is associated with true ID (AI/ID), as there is still a lack of a gold standard for differentiation between $\mathrm{Al}$ and AI/ID. However, as therapies to overcome anemia differ, proper diagnosis and understanding of underlying pathophysiological regulations are necessary.
Objectives: The aim of the study was to evaluate the clinical efficiency of hepcidin, a key regulator of iron metabolism, in the diagnosis of IDA, as well as the differential diagnosis of $\mathrm{AI} / \mathrm{ID}$ and $\mathrm{Al}$ in patients with $\mathrm{RA}$.

Methods: The study was undertaken 96 patients with RA, 67 of them were diagnosed anemia according to WHO criteria $(104,3 \pm 21,4 \mathrm{~g} / \mathrm{l})$. Anemic patients and anemia-free patients with RA $(n=29)$ were comparable $(p>0.05)$ in age $(44.4 \pm 14.8$ and $49.8 \pm 9.3$ years), disease duration $(73.5 \pm 65.4$ and $59.8 \pm 48.3$ months) and DAS28 $(6.3 \pm 1.6$ and $5.9 \pm 1.9)$. All cases were subjected to following tests: complete blood count with peripheral smear, serum C-reactive protein, serum interleukin-6, iron studies, serum soluble transferrin receptor (sTfR), and serum hepcidin. Patients with RA and anemia were divided two groups: 25 patients with IDA and 42 - with AI. The Al cases were subdivided into pure Al and AI with coexistent ID $(n=15)$.

Results: The mean serum hepcidin concentration was significantly increased in pure Al patients $(123.85 \pm 25.8 \mathrm{ng} / \mathrm{mL})$ as compared to those in IDA patients $(63.9 \pm 22.8 \mathrm{ng} / \mathrm{mL}, \mathrm{P}<0.05)$ and anemia-free patients with RA $(88.1 \pm 39.09 \mathrm{ng} /$ $\mathrm{mL})$. Also, compared to pure Al patients [normal sTfR levels $(<3 \mu \mathrm{g} / \mathrm{mL})$ ], the serum hepcidin concentration was reduced significantly in Al patients with ID [high sTfR levels $(\geq 3 \mu \mathrm{g} / \mathrm{mL})$ ] with a mean of $79.0 \pm 23.97 \mathrm{ng} / \mathrm{mL}$

Conclusion: Hepcidin measurement can provide a useful tool for differentiating Al from IDA and also help to identify an iron deficiency in Al patients. This might aid in the appropriate selection of therapy for these patients.

Disclosure of Interests: None declared

DOI: 10.1136/annrheumdis-2021-eular.3303

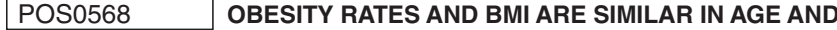 SEX MATCHED RHEUMATOID ARTHRITIS, PSORIATIC ARTHRITIS AND SPONDYLOARTHRITIS PATIENTS}

G. K. Yardımcı ${ }^{1}$, B. Farisoğulları ${ }^{1}$, E. C. Bolek ${ }^{1}$, E. Bilgin ${ }^{1}$, E. Duran ${ }^{1}$, G. Ayan ${ }^{1}$ Z. Özsoy ${ }^{1}$, G. Sandal Uzun ${ }^{1}$, L. Kılıç ${ }^{1}$, A. Akdoğan ${ }^{1}$, O. Karadag ${ }^{1}$, Ş. A. Bilgen ${ }^{1}$, S. Kiraz ${ }^{1}$, U. Kalyoncu ${ }^{1}$, A. İ. Ertenli ${ }^{1} .{ }^{1}$ Faculty of Medicine; Hacettepe University, Rheumatology, Ankara, Turkey

Background: Obesity has been suggested to be a chronic inflamatory condition and therefore, obesity may be considered as a risk factor for developing immune-mediated diseases, including inflammatory arthritis. In larger biologic registiries, obesity was found frequently in psoriatic arthritis than other inflammatory diseases such as rheumatoid arthritis and spondyloarthritis. [1-4]. However, obesity may be a reason of aging, moreover, there are strong sex differences between those diseases.

Objectives: The aim of this study was to evaluate the obesity rates in sex and aged matched patients with inflammatory arthritis before the initation of biological therapy.

Methods: HUR-BIO (Hacettepe University Biologic Registry) is a prospective, single center database of biological treatments since 2005 and to date 5635 patients have been recorded. Demographic, clinical and laboratory data before bDMARD of SpA, RA and PsA patients were noted. The patients were divided into two groups: non-obese patients $\left(<30 \mathrm{~kg} / \mathrm{m}^{2}\right)$ and obese $\left(\geq 30 \mathrm{~kg} / \mathrm{m}^{2}\right)$ patients. When investigeting the changes in BMI by diagnosis, the effects of gender and age were adjusted using two-way ANOVA and ANCOVA tests. The selection was made for the gender and age indifferences of the relevant groups by using propensity score.

Results: 5059 patients' (1834 RA, 2741 SpA and 484 PsA) BMI data before the bDMARD treatments were avaliable and analysed. Baseline characteristics of RA, SpA and PsA patients were given in Table 1. $72.3 \%$ of the RA patients were seropositive. HLAB27 was positive in $64.7 \%$ and $22.9 \%$ of the SpA and PsA patients. Anti-TNF therapy was started as first bDMARD in $57.2 \%$ of the RA patients, others were started with non-Anti-TNF bDMARDs. In SpA (99.2\%) and PsA (100\%) patients anti-TNFs were the first biologics. Overall, the proportion of obese patients was significantly higher in RA and PsA than in SpA patients (Table 1) and age and sex affected BMl significantly $(p<0.001)$ (Figure 1). After adjusting age and sex indifference between groups, the difference between the BMI of the patients disappeared (Table 1)

Table 1. Baseline characteristics and BMI of the patients

\begin{tabular}{|c|c|c|c|c|c|}
\hline & & RA & SpA & PsA & $p$ \\
\hline \multirow{6}{*}{$\begin{array}{l}\text { All bDMARD } \\
\text { patients }\end{array}$} & $\mathrm{N}$ & 1834 & 2741 & 484 & \\
\hline & Female, n (\%) & $1470(80.2)$ & $1257(45.9)$ & $334(69.0)$ & $0.000^{*}$ \\
\hline & Age, years* & $52.9 \pm 13.4$ & $43.1 \pm 11.4$ & $47.4 \pm 12.2$ & $0.000^{*}$ \\
\hline & Disease duration, years ${ }^{*}$ & $11(7-17)$ & $8(5-13)$ & $7(3-12)$ & $0.000^{*}$ \\
\hline & Body mass index ${ }^{\star}$ & $29.6 \pm 6.5$ & $27.7 \pm 5.4$ & $29.2 \pm 5.8$ & $0.000^{*}$ \\
\hline & Obesity, n (\%) & $811(44.2)$ & $815(29.7)$ & $199(41.1)$ & $0.000^{*}$ \\
\hline \multirow{6}{*}{$\begin{array}{l}\text { Age and sex } \\
\text { matched } \\
\text { group }\end{array}$} & $\mathbf{N}$ & 481 & 483 & 484 & \\
\hline & Female, n (\%) & $315(65.7)$ & $324(67.1)$ & $334(69.0)$ & 0.545 \\
\hline & Age, years* & $47(36-59)$ & $48(39-57)$ & $47(38-56)$ & 0.691 \\
\hline & Disease duration, years ${ }^{*}$ & $10(6-15)$ & $5(5-13)$ & $7(3-12)$ & $0.000^{*}$ \\
\hline & Body mass index* & $28.5 \pm 6.1$ & $28.5 \pm 5.8$ & $29.2 \pm 5.8$ & 0.150 \\
\hline & Obesity, n (\%) & $183(38.0)$ & $176(36.4)$ & $199(41.1)$ & 0.316 \\
\hline
\end{tabular}

* Mean \pm S.D ${ }^{\ngtr}$ Median (IQR) 